\title{
Validation of the Brazilian version of the WHODAS 2.0 for people affected by leprosy
}

\author{
Jardel Gonçalves de Sousa Almondes ${ }^{\mathrm{a}}$, Shamyr Sulyvan de Castro ${ }^{\mathrm{a}}$, \\ Paula Sacha Frota Nogueirab ${ }^{\mathrm{b}}$, Reagan Nzundu Boigny ${ }^{\mathrm{a}} \&$ \\ Carlos Henrique Alencar ${ }^{\mathrm{a}}$ \\ a Programa de Pós-graduação em Saúde Pública, Departamento de Saúde \\ Comunitária, Faculdade de Medicina, Universidade Federal do Ceará, \\ Fortaleza, Ceará, Brasil; \\ ORCIDs: https://orcid.org/0000-0001-6376-4276; https://orcid.org/0000-0 \\ 002-2661-7899; https://orcid.org/0000-0002-4487-5509; https://orcid.org/0 \\ 000-0003-2967-532X \\ ${ }^{\mathrm{b}}$ Departamento de Enfermagem, Faculdade de Farmácia, Odontologia e \\ Enfermagem, Universidade Federal do Ceará, Fortaleza, Ceará, Brasil; \\ ORCID: https://orcid.org/0000-0003-4053-1722
}

Submitted 31 August 2020; Accepted 16 December 2020

\begin{abstract}
Summary The International Classification of Functioning has an impact on the way clinical information related to functioning are thought and worked on. The use of instruments such as WHODAS 2.0 allows the practical and routine incorporation of an instrument based on the ICF in the health care of people affected by leprosy. For clinical and research purposes, measurement instruments need to be validated based on their psychometric properties. This study aimed to validate the WHODAS 2.0 for use in people affected by leprosy. The instruments used were WHODAS 2.0 version of 36 questions, World Health Organization Quality of Life (WHOQOLbref) and Screening of Activity Limitation and Safety Awareness (SALSA). Data were also collected on disability grade and eye-hand-foot score. The psychometric properties evaluated were internal consistency, convergent and divergent construct and criterion validity. Cronbach's $\alpha$ coefficient ranged from 0.76 to 0.91 , revealing good internal consistency. The convergent validity showed a moderate correlation between the total score of WHODAS 2.0 and WHOQOL-bref (rho $=-0.67 ; p<$ 0.05 ) and strong correlation between WHODAS 2.0 and SALSA (rho $=0.72 ; p<$ $0.05)$. For related domains, the correlation was moderate to strong. An exception was the weak correlation with the Interpersonal Relations domain. The divergent validity showed weak correlations. The criterion validity showed a significant result between WHODAS 2.0 and disability grade $(p=0.01)$. The correlation between WHODAS 2.0 and eye-hand-foot score showed a weak but significant correlation
\end{abstract}

Correspondence to: Carlos Henrique Alencar, Public Health Post Graduate Program, Faculty of Medicine/ Federal University of Ceará. Professor Costa Mendes St., 1608, bloco didático, 5th floor, Rodolfo Teófilo, Zip 60430-140, Fortaleza, Ceará, Brasil (Tel.: 5585 3366-8045; e-mail: carllosalencar@ufc.br) 
(rho $=0.23 p=0.003$ ). WHODAS 2.0 has valid and reliable psychometric characteristics for use in people affected by leprosy.

Keywords: Validation study, leprosy, functioning, WHODAS 2.0

\section{Introduction}

Leprosy is a chronic infectious disease caused by Mycobacterium leprae, in which transmission occurs from an infected person, especially one with untreated multibacillary disease, through the upper respiratory tract, infecting people susceptible to the disease. ${ }^{1}$

Leprosy mainly affects the superficial nerves of the skin and peripheral nerve trunks, but it can also affect the eyes and internal organs. If untreated, it may evolve into more severe forms. In general, the evolution of the disease occurs slowly and progressively, and can lead to physical disabilities. ${ }^{2}$

Brazil stands out with India and Indonesia in the global picture of leprosy; together they are responsible for $79 \%$ of the global burden of the disease. ${ }^{3}$ Between 2009 and 2018, 311,384 new leprosy cases were diagnosed in Brazil. In the same period, 20,785 new leprosy cases were diagnosed with a degree of visible physical disabilities, all of which show Brazil to be highly endemic for the disease. ${ }^{4}$

The prevention of disabilities in a person with leprosy must be carried out through a dermato-neurological examination. This examination allows for early diagnosis and intervention at the moment when peripheral neural involvement begins, reducing the chances of developing physical disabilities. When present, these physical disabilities can cause problems such as decreased work capacity and absenteeism, limitation of social life and psychological problems, and are also responsible for the stigma and historical prejudice towards people with the disease. ${ }^{5}$

The World Health Organization Disability Assessment Schedule (WHODAS 2.0) is a generic assessment tool developed by WHO to provide a standardized method of measuring health and disability in a cross-cultural way. WHODAS 2.0 was translated into Portuguese by Castro et al. (2015) and this version was officially recognized by WHO for Brazilian Portuguese. $^{6}$

The conceptual structure of the International Classification of Functioning-ICF, places health and disability on a continuum, defining disability as "a reduction in each domain of functioning". It is etiologically neutral and does not depend on the antecedent disease or previous health conditions for its application. This characteristic makes it possible to focus attention directly on functioning and disability. ${ }^{7}$

The instrument provides the functioning level of six domains of life: Cognitionunderstanding and communication; Mobility—movement and locomotion; Self-care-dealing with your own hygiene, dressing, eating and being alone; Getting along-interactions with other people; Life activities-domestic responsibilities, leisure, work and school; Participation-participating in community activities and in society. ${ }^{7}$

The use of instruments that assess physical limitations, functioning in specific activities and restrictions on participation in life situations, allows the understanding of the impact of the disease on the health of individuals with leprosy, facilitating the establishment of more complex and efficient therapeutic measures, as well as the prevention of disabilities.

In Brazil, the use of instruments based on the theoretical framework of the ICF for the measurement of clinical and statistical data on people affected by leprosy is still developing. 
In this perspective, WHODAS 2.0 presents itself as a promising and practical instrument, built along the lines of the ICF, that allows the measurement of functioning and disability.

This is a pioneering research that analyzed the psychometric properties of the Brazilian version of WHODAS 2.0 in people undergoing treatment for leprosy, with the aim of validating WHODAS 2.0 for use in individuals affected by leprosy.

\section{Material and methods}

This is a validation study, carried out in the clinics of the Dermatology Reference Center Dona Libânia (CDERM), linked to the Health Department of the State of Ceará. A non-probabilistic sample size of 155 people were invited to participate in the research and its final composition resulted from the period available for data collection-September to December 2019.

The study included individuals over 18 years of age with a confirmed diagnosis of leprosy, accompanied by the reference service, undergoing drug treatment from the second supervised dose and who agreed to participate in the research after reading and signing the Informed Consent Form. The research excluded those who had a mental condition that altered cognition and/or the understanding of the questions in the used questionnaires. Individuals not able to attend the clinic and those who had other conditions previously diagnosed that already compromised their activity and participation in society were also excluded.

Data collection was performed in a single visit with each participant, through an interview, using the research questionnaires. The interviews were conducted by the main researcher, a physiotherapist, and a team composed by nursing students, all properly trained in the use of the research instruments.

A questionnaire was used to document sociodemographic and clinical data based on the IFC checklist and the notification form of the National System of Notifiable Diseases for leprosy, containing the variables: sex, age, marital status, years of formal education, occupation, number of skin lesions, number of affected nerves, smear microscopy, clinical form and RJ operational classification of the disease.

For the validation of WHODAS 2.0, the instrument itself (in its full version of 36 questions), the WHOQOL-bref, the SALSA questionnaire, data for assessing the disability grade and eyehand-foot score (EHF) were used. WHOQOL-bref and SALSA were selected because they have similar constructs to WHODAS 2.0.

The WHODAS 2.0 score is given through a response on a Likert scale ranging from 1 to 5 and coding the results by domain (by the sum of the scores in each of the items in that domain) and by the total score, after which the values are transformed on a scale of 0 to 100 , as indicated in the WHODAS 2.0 manual. The higher the score, the greater the disability. The total score is calculated considering the 36 items or considering all items except those referring to domain 5.2 "daily activities" - work/school (total of 32 items), in case the participants do not work or do not study. ${ }^{7}$

The World Health Organization Quality of Life (WHOQOL-bref) is an abbreviated version of the WHO Quality of Life instrument (WHOQOL-100) and has 26 items covering four domains of quality of life: physical (seven items), psychological (six items), social (three items) and environmental (eight items), with two more general questions about health and quality of life. The WHOQOL-bref also has a scale of Likert responses ranging from 1 to 5 . The scores for each domain, as well as the total score, can be calculated using a linear scale from 0 to 100 , where higher scores reflect better quality of life. WHOQOL-bref is already translated and validated for use in Brazil. ${ }^{8}$ 
The Screening of Activity Limitation and Safety Awareness (SALSA) scale is an instrument validated in Brazil, with application in different sociocultural scenarios, in patients who have or have had leprosy, diabetes and other peripheral neuropathies. ${ }^{9}$ It covers four domains that involve: eyes, hands (dexterity and work), feet (mobility) and self-care. The score ranges from 10 to 80 , the lower the score, the lower the difficulty with activities of daily living and higher scores are indicative of increasing levels of activity limitation. ${ }^{10}$

To obtain the WHO disability grade for leprosy, six body sites are evaluated, which are graded as 0 - without physical disability, 1 - decreased strength and/or decreased or loss of sensation in the eyes, hands or feet or 2 - visible damage to the eyes, hands or feet. The maximum grade at any site is recorded as the individual's disability grade, ranging from $0-2$. To obtain the eye-hand-foot score (EHF), the disability grades in each of the six locations are added up, leading to a result between 0 and $12 .^{2}$ These data were obtained from the individuals' medical records.

All data were entered into the Epi Info version 7.2 software and subsequently analyzed using the Stata 15.1 statistical software. The level of significance adopted was $95 \%$. The profile of the research population was characterized according to absolute and relative frequencies, as well as measures of central trend and dispersion.

The WHODAS 2.0 reliability analysis was performed using the internal consistency criterion, assessed by Cronbach's alpha coefficient. Alpha values above 0.75 were considered satisfactory, which corresponds to a high internal consistency. ${ }^{11}$

The Spearman correlation coefficient was used to test the convergent and divergent construct validity of WHODAS 2.0, with WHOQOL-bref and SALSA, comparing the related and unrelated domains, respectively. Criterion validity was verified by the Kruskal-Wallis test between the total values and by WHODAS 2.0 domains and the degree of disability as well as by the Spearman correlation of the total scores and by WHODAS 2.0 domains with the EHF score. For the correlation tests, the results were considered weak when between 0.1 and 0.39 ; moderate from 0.4 to 0.69 ; strong from $0.7 .^{12}$

This research followed the ethical principles of Resolution 466/2012 of the National Health Council, ${ }^{13}$ starting after the approval by the Ethics Committee of the Federal University of Ceará (Opinion number 3,554,297) and by the Ethics Committee of the Reference Center in Dermatology Dona Libânia (Opinion number 3,573,192).

\section{Results}

155 individuals were interviewed, mostly men $(68 \%)$, mean age 47.9 years ( \pm 15.6 years). The average years of study was 7.4 ( \pm 4.8 years), and $33 \%$ were married. Most participants did not work, either due to unemployment related to their health condition $(31.6 \%)$, unemployment for other reasons (3.2\%), being retired due to age or due to disability (23.2\%) (Table 1).

There was an average of 7.4 skin lesions and a predominance of multibacillary cases $(89.6 \%)$, Borderline classification $(57.6 \%)$ and with positive sputum smear microscopy $(63 \%)$. People without physical disability were more frequent (42.3\%), the EHF score had a mean of 1.6 and the average number of affected nerves was 1.4 (Table 1).

The results of the questionnaires expressed as means and standard deviations are shown in Table 2. WHODAS 2.0 had an average score of 29.4 and the most affected domain was Participation with a score of 41.2. WHOQOL-bref had an average result of 55.7 with the Physical domain obtaining the lowest result of 51.2. For the SALSA scale, the mean total score was 36, with the Mobility domain being the most compromised with an average of 10.6. 
Table 1. Absolute and relative frequencies of the demographic and clinical characteristics of the leprosy cases evaluated

\begin{tabular}{|c|c|c|}
\hline Variable & $n$ & $\%$ \\
\hline \multicolumn{3}{|l|}{ Sex } \\
\hline Male & 106 & 68.4 \\
\hline Female & 49 & 31.6 \\
\hline \multicolumn{3}{|l|}{ Marital status } \\
\hline Single & 46 & 29.7 \\
\hline Married & 52 & 33.5 \\
\hline Separated & 15 & 9.7 \\
\hline Divorced & 6 & 3.9 \\
\hline Widowed & 8 & 5.2 \\
\hline Partnership & 28 & 18 \\
\hline \multicolumn{3}{|l|}{ Occupation } \\
\hline Paid work & 24 & 15.5 \\
\hline Self-employed & 18 & 11.6 \\
\hline Student & 4 & 2.6 \\
\hline Housewife & 10 & 6.5 \\
\hline Retired & 36 & 23.2 \\
\hline Unemployed (health reasons) & 49 & 31.6 \\
\hline Unemployed (other reasons) & 5 & 3.2 \\
\hline Other & 9 & 5.8 \\
\hline \multicolumn{3}{|l|}{ Operational classification } \\
\hline Paucibacillary & 16 & 10.4 \\
\hline Multibacillary & 138 & 89.6 \\
\hline \multicolumn{3}{|l|}{ RJ Classification } \\
\hline Indeterminate & 0 & - \\
\hline Tuberculoid & 12 & 10.2 \\
\hline Borderline & 68 & 57.6 \\
\hline Lepromatous & 38 & 32.2 \\
\hline \multicolumn{3}{|l|}{ Skin smear } \\
\hline Positive & 92 & 63 \\
\hline Negative & 49 & 33.6 \\
\hline Not performed & 2 & 1.4 \\
\hline Ignored & 3 & 2.0 \\
\hline \multicolumn{3}{|l|}{ Disability grade } \\
\hline 0 & 63 & 42.3 \\
\hline 1 & 47 & 31.5 \\
\hline \multirow[t]{2}{*}{2} & 39 & 26.2 \\
\hline & Mean & Standard deviation \\
\hline Age & 47.9 & 15.6 \\
\hline Years of study & 7.4 & 4.8 \\
\hline Number of skin lesions & 7.4 & 9.7 \\
\hline Number of affected nerves & 1.4 & 1.8 \\
\hline EHF & 1.6 & 1.9 \\
\hline
\end{tabular}

The analysis of the internal consistency of WHODAS 2.0 and its domains shows that for the total score the coefficient was 0.95 and for the scores per domain, its value ranged between 0.76 to 0.91 (Table 3 ). 
Table 2. Description of the total values and by domains of the WHODAS 2.0, WHOQOL-bref and SALSA questionnaires

\begin{tabular}{lcc}
\hline Variable & Mean & Standard deviation \\
\hline WHODAS 2.0 & 28.9 & \\
Cognition & 38.4 & 22.7 \\
Mobility & 22.1 & 30.4 \\
Self-care & 20.1 & 25.8 \\
Getting along & 38.9 & 21.3 \\
Life activities (domestics) & 20.9 & 34.2 \\
Life activities (school/work) & 19.9 & 24.0 \\
Life activities & 41.2 & 17.8 \\
Participation & 29.4 & 25.8 \\
Total & & 19.3 \\
WHOQOL-bref & 51.2 & \\
Physical & 62.4 & 21.7 \\
Psychological & 62.6 & 16.5 \\
Social & 52.7 & 22.5 \\
Environmental & 55.7 & 16.2 \\
Total & & 15.8 \\
SALSA & 10.6 & \\
Mobility & 5.5 & 4.2 \\
Self-care & 12 & 2.5 \\
Work & 7.7 & 6.2 \\
Dexterity & 36 & 3.7 \\
Total & & 14.5 \\
\hline
\end{tabular}

Table 3. Analysis of the Cronbach's alpha of WHODAS 2.0 and its domains

\begin{tabular}{lc}
\hline WHODAS 2.0 & Cronbach's alpha \\
\hline Cognition & 0.80 \\
Mobility & 0.87 \\
Self-care & 0.82 \\
Getting along & 0.76 \\
Life activities (domestics) & 0.88 \\
Life activities (school/work) & 0.86 \\
Life activities & 0.91 \\
Participation & 0.86 \\
Total & 0.95 \\
\hline
\end{tabular}

Table 4 presents the result of the convergent and divergent construct validity analysis. There was an inverse relationship between WHODAS 2.0 domains in relation to WHOQOL-bref domains.

The evaluation of convergent validity between the domains showed a strong and significant correlation between Participation domain of WHODAS 2.0 with Physical domain of WHOQOL-bref (rho $=-0.71$ ), WHODAS 2.0 Life activities (school/work) with the Physical domain of WHOQOL-bref (rho $=-0.70$ ) and between the total scores of WHODAS 2.0 and SALSA (rho $=-0.72$ ). The other related domains showed a moderate and significant correlation that ranged from -0.44 to -0.69 .

Weak correlation coefficients were observed between the unrelated domains in the analysis of the divergent construct validity: Cognition of WHODAS 2.0 and Environmental of 
Table 4. Correlation between the domains of the WHODAS 2.0 scale versus the domains of the WHOQOL-bref scale and the SALSA scale, convergent and divergent validities

\begin{tabular}{|c|c|c|c|c|c|c|c|c|c|}
\hline & \multicolumn{8}{|c|}{ WHODAS 2.0} & \multirow[b]{2}{*}{ Total } \\
\hline & 1 & 2 & 3 & 4 & 5.1 & 5.2 & 5 & 6 & \\
\hline \multicolumn{10}{|l|}{$\begin{array}{l}\text { WHOQOL- } \\
\text { bref }\end{array}$} \\
\hline Physical & $-0.58 *$ & $-0.69 *$ & $-0.55 *$ & $-0.42 *$ & $-0.59 *$ & $-0.70 *$ & $-0.53^{*}$ & $-0.71 *$ & $-0.73 *$ \\
\hline Psychological & $-0.44 *$ & $-0.44^{*}$ & $-0.37 *$ & $-0.34 *$ & $-0.40^{*}$ & -0.27 & $-0.34^{*}$ & $-0.51 *$ & -0.51 \\
\hline Social & $-0.41^{*}$ & $-0.37 *$ & $-0.33^{*}$ & $-0.30 *$ & $-0.41^{*}$ & -0.34 & $-0.37 *$ & $-0.45^{*}$ & -0.48 \\
\hline Environmental & $-0.36^{*}$ & $-0.37 *$ & $-0.30 *$ & $-0.32 *$ & $-0.35^{*}$ & -0.35 & $-0.32 *$ & $-0.46^{*}$ & -0.45 \\
\hline $\begin{array}{l}\text { Total } \\
\text { SALSA }\end{array}$ & $-0.55^{*}$ & $-0.58 *$ & $-0.47^{*}$ & $-0.41 *$ & $-0.54 *$ & $-0.55^{*}$ & $-0.48 *$ & $-0.67 *$ & $-0.67 *$ \\
\hline Mobility & $0.42 *$ & $0.66^{*}$ & $0.49 *$ & $0.39 *$ & $0.50 *$ & 0.41 & $0.43^{*}$ & $0.54 *$ & 0.61 \\
\hline Self-care & $0.43^{*}$ & $0.67 *$ & $0.59 *$ & $0.34 *$ & $0.53^{*}$ & 0.37 & $0.45^{*}$ & $0.51 *$ & 0.62 \\
\hline Work & $0.48^{*}$ & $0.64 *$ & $0.63^{*}$ & $0.31 *$ & $0.61 *$ & $0.46 *$ & $0.49 *$ & $0.54 *$ & 0.64 \\
\hline Dexterity & $0.42 *$ & $0.57^{*}$ & $0.59^{*}$ & $0.28 *$ & $0.50 *$ & 0.30 & $0.42 *$ & $0.49^{*}$ & 0.57 \\
\hline Total & $0.53 *$ & $0.75^{*}$ & $0.65^{*}$ & $0.39 *$ & $0.63^{*}$ & $0.50 *$ & $0.53^{*}$ & $0.61 *$ & $0.72 *$ \\
\hline
\end{tabular}

Note: $* p<0,001$; WHODAS 2.0 domains: (1) Cognition; (2) Mobility; (3) Self-care; (4) Getting along; (5.1) Life activities (domestics); (5.2) Life activities (school/work); (5) Life activities; (6) Participation.

WHOQOL-bref (rho $=-0.36$ ), Mobility of WHODAS 2.0 and Social of WHOQOL-bref (rho $=-0.37$ ), Self-care of WHODAS 2.0 with Psychological of WHOQOL-bref (rho = -0.37 ), WHODAS 2.0 Getting along with SALSA Dexterity (rho $=0.28$ ), Life activities (domestic) of WHODAS 2.0 with WHOQOL-bref Environmental (rho $=-0.35$ ), Life activities (work/school) of WHODAS 2.0 with WHOQOL-bref Psychological (rho $=-0.27$ ). The only exception was the WHODAS 2.0 Participation domain, which showed a moderate correlation with the WHOQOL-bref and SALSA unrelated domains.

When associated with the disability grade, the WHODAS 2.0 domains that had statistical significance were Cognition $(p=0.02)$ and Participation $(p=0.03)$. However, for the other domains there was an increase in the value of quartiles and medians with an increase in the degree of physical disability, even without statistical significance. Emphasis should be given to the domain of Domestic activities with an increase of 10 points in each degree of physical disability and School/work activities, with values that almost doubled in each degree. It was also found that the total value of WHODAS 2.0 showed a statistically significant difference with the IG $(p=0.01)$, with median values of $17.9,32$ and 35.8 points for each degree of disability, respectively (Table 5).

When verifying the criterion validity, the correlation between WHODAS 2.0 and its domains with the EHF score showed statistically significant results, but with weak values. The Life activities domain had the lowest correlation (rho $=0.16 p=0.04)$, the Mobility domain the highest correlation $(r h o=0.21 p=0.01)$ and the total score had a correlation value of rho $=0.23$ and $p=0.003$. For the other domains, the results were Cognition (rho =0.17 $p=0.03$ ), Self-care (rho $=0.19 p=0.01$ ), Getting along (rho $=0.20 p=0.01)$, Life activity (domestic) (rho $=0.21 p=0.008)$, Life activity (school work) (rho $=0.20 p<0.19)$, Participation (rho = $0.18 p=0.02$ ).

\section{Discussion}

The first psychometric property evaluated was the internal consistency and Cronbach's alpha values which point to high internal consistency, both for each of the domains and for the total 
Table 5. Criterion validity between WHODAS 2.0 and disability grade

\begin{tabular}{|c|c|c|c|c|c|}
\hline Variable & Total & $\mathrm{P} 25$ & Median & P75 & $p$-value \\
\hline \multicolumn{6}{|c|}{ WHODAS-Cognition } \\
\hline Grade 0 & 63 & 5 & 15 & 35 & \multirow[t]{3}{*}{0.02} \\
\hline Grade 1 & 47 & 15 & 30 & 50 & \\
\hline Grade 2 & 39 & 15 & 30 & 50 & \\
\hline \multicolumn{6}{|c|}{ WHODAS-Mobility } \\
\hline Grade 0 & 63 & 6.2 & 25 & 56.2 & \multirow[t]{3}{*}{0.06} \\
\hline Grade 1 & 47 & 6.2 & 50 & 68.7 & \\
\hline Grade 2 & 39 & 25 & 43.7 & 68.7 & \\
\hline \multicolumn{6}{|c|}{ WHODAS-Self-care } \\
\hline Grade 0 & 63 & 0 & 10 & 30 & \multirow[t]{3}{*}{0.14} \\
\hline Grade 1 & 47 & 0 & 20 & 50 & \\
\hline Grade 2 & 39 & 0 & 20 & 50 & \\
\hline \multicolumn{6}{|c|}{ WHODAS—Getting along } \\
\hline Grade 0 & 63 & 0 & 8.3 & 25 & \multirow[t]{3}{*}{0.08} \\
\hline Grade 1 & 47 & 0 & 8.3 & 41.6 & \\
\hline Grade 2 & 39 & 8.3 & 25 & 41.6 & \\
\hline \multicolumn{6}{|c|}{ WHODAS - Life activities (domestics) } \\
\hline Grade 0 & 63 & 0 & 20 & 50 & \multirow[t]{3}{*}{0.055} \\
\hline Grade 1 & 47 & 10 & 30 & 70 & \\
\hline Grade 2 & 39 & 10 & 40 & 90 & \\
\hline \multicolumn{6}{|c|}{ WHODAS_Life activities (school/work) } \\
\hline Grade 0 & 22 & 0 & 7.14 & 28.5 & \multirow[t]{3}{*}{0.27} \\
\hline Grade 1 & 12 & 3.57 & 17.8 & 39.2 & \\
\hline Grade 2 & 8 & 3.57 & 35.7 & 53.5 & \\
\hline \multicolumn{6}{|c|}{ WHODAS_Life activities } \\
\hline Grade 0 & 63 & 4 & 12.5 & 29 & \multirow[t]{3}{*}{0.13} \\
\hline Grade 1 & 47 & 4 & 20.8 & 29 & \\
\hline Grade 2 & 39 & 4 & 25 & 37.5 & \\
\hline \multicolumn{6}{|c|}{ WHODAS_Participation } \\
\hline Grade 0 & 63 & 16.6 & 29 & 50 & \multirow[t]{3}{*}{0.03} \\
\hline Grade 1 & 47 & 29 & 41.6 & 66.6 & \\
\hline Grade 2 & 39 & 20.8 & 54 & 66.6 & \\
\hline \multicolumn{6}{|l|}{ WHODAS } \\
\hline Grade 0 & 63 & 10.3 & 17.9 & 35.8 & \multirow[t]{3}{*}{0.01} \\
\hline Grade 1 & 47 & 16 & 32 & 44.3 & \\
\hline Grade 2 & 39 & 16.9 & 35.8 & 48 & \\
\hline
\end{tabular}

score of the questionnaire. The analysis of internal consistency is based on the correlation of items of the same construct with each other and on the correlation of each item with the total score of this construct. ${ }^{14}$ Instruments that have internal consistency or homogeneity are instruments whose subparts measure the same concept. ${ }^{15}$ Therefore, the result of this work demonstrates that the items of the WHODAS 2.0 domains are coherent in addressing the functioning of each of the domains in people with leprosy. Similar values of Cronbach's alpha were found in the studies by Barbosa et al. ${ }^{16}$ and Castro et al. ${ }^{17}$

In the convergent construct validity, this study obtained moderate and strong correlation coefficients between all related domains of WHODAS 2.0 with those of WHOQOL-bref and SALSA, except for the Interpersonal relations domain of WHODAS 2.0, which had a weak correlation with the Social relations domain of WHOQOL-bref. However, when the correlation between the total scores of the three questionnaires was observed, WHODAS 2.0 and WHOQOL-bref had moderate correlation whereas WHODAS 2.0 and SALSA had a strong 
correlation. It is noteworthy that there were a smaller number of respondents in the WHODAS 2.0 Life activities (school/work) domain, which is consistent with the characterization of the sample, as approximately $60 \%$ of them did not work or perform school activities.

Construct validity refers to the relationship between theoretical concepts and their operationalization. It demonstrates the epistemic relationship that must exist between a concept and its measure. ${ }^{14}$ In the convergent construct analysis, this validity refers to the degree to which a measurement instrument is consistently related to other similar measurements, derived from the same theory and concepts being measured. ${ }^{18}$

The study by Park et al. ${ }^{19}$ also found moderate and weak correlation coefficients using the WHOQOL-bref as a correlated scale to test convergent validity. As in the present study, it was observed that the Getting along domain was the one with the lowest correlation coefficient when tested as a similar construct between the scales. ${ }^{19}$ Also, in the study of Castro et al. ${ }^{17}$ the correlation between the WHODAS 2.0 Interpersonal relations domain with WHOQOLbref Social relations was weak. The other domains showed a moderate correlation between the other similar associated constructs, as in the present study.

The weak correlation in the WHODAS 2.0 Getting along domain with WHOQOL-bref Social relations, found in the present study, can be explained by the inconsistency in the answers to the questions of the two instruments that deal with the participants' sexual life. While the vast majority of respondents considered having mild or no difficulty with sexual practice, only half considered themselves satisfied or very satisfied with their sex life. It is also worth mentioning that these were the questions with the highest number of missing responses.

Divergent construct validity tests the hypothesis that the measure in question is not unduly related to different constructs, that is, with variables from which it should diverge. ${ }^{20}$ In the divergent validity test, the unrelated domains showed a weak correlation coefficient, as expected, with the exception of the WHODAS 2.0 Participation domain, which still presented a moderate correlation. This may suggest that, for people with leprosy, the issues that form each of the WHOQOL-bref and SALSA constructs are covered, even if in part, by the issues that form the WHODAS 2.0 Participation domain. Weak coefficients between noncorrelated constructs were also found in the study of Castro et al. $^{17}$

The disability grade is adopted by the WHO for monitoring people with leprosy as an epidemiological indicator, which can be used to determine the early diagnosis and also evaluate the success of the therapeutic measures adopted. Disability grade assessment is an important tool in identifying patients at greater risk of developing reactions and new disabilities, during treatment, at the end of chemotherapy and after discharge. ${ }^{2}$ Complications resulting from disabilities can be responsible for permanent sequelae to the individual and result in social and psychological damage that directly interfere with their quality of life. ${ }^{21}$ Thus, observing the positive or negative variations of WHODAS 2.0 in accordance with the disability grade, it can be inferred that WHODAS 2.0 has sensitivity to change according to what was verified by the disability grade criterion.

In WHODAS 2.0 criterion validity by disability grade, only two domains and the total score of the scale showed statistical significance. It is assumed that the other domains did not obtain satisfactory statistical evidence due to the small number of the sample stratified between the disability grade categories. However, when observing the quartile values by domain, it is clear that the higher the disability grade of each domain, the greater the values expressed by the median and quartiles. This denotes a positive association between the installation of increasing degrees of disability with higher values expressed by WHODAS 2.0. Moderate 
and strong correlations were also found in other studies, which validated WHODAS 2.0 for individuals with HIV/AIDS, people with osteoarthritis and for individuals with multiple sclerosis. ${ }^{16,22,23}$

The EHF score is an alternative to the disability grade to detail the data on disabilities, being more sensitive to changes than the disability grade itself. ${ }^{2}$ In this research, the weak correlations found between WHODAS 2.0 and its domains with the EHF score can be explained by the low average of the EHF score. Some studies have also found low values of the EHF score. ${ }^{24,25}$ A different result was expressed in the study of Heidinger et al., ${ }^{26}$ which obtained an EHF score of 7.

Regarding the limitations of this study, since this was a cross-sectional study it was not possible to determine other psychometric properties such as test-retest reliability. A second limitation was the non-use of a cognitive screening instrument as an inclusion/exclusion criterion, this decision being left to the investigator at the time of the interview.

Our findings allow us to state that the Portuguese version of the WHODAS 2.0 is valid and reliable to use in people affected by leprosy.

\section{Conflict of interest}

All authors declare that the answer to the question on competing interest form are all 'No', and therefore have nothing to declare.

\section{Details of contributors}

Jardel Gonçalves de Sousa Almondes: project design; data collect; analysis and interpretation of data; writing of the article; relevant critical review of the intellectual content and final approval of the version to be published.

Shamyr Sulyvan de Castro: analysis and interpretation of data; writing of the article; relevant critical review of the intellectual content and final approval of the version to be published.

Paula Sacha Frota Nogueira: analysis and interpretation of data; writing of the article; relevant critical review of the intellectual content and final approval of the version to be published

Reagan Nzundu Boigny: interpretation of data; relevant critical review of the intellectual content and final approval of the version to be published.

Carlos Henrique Alencar: project design; analysis and interpretation of data; writing of the article; relevant critical review of the intellectual content and final approval of the version to be published.

\section{Ethics approval}

Ethics Committee of the Federal University of Ceará: Opinion number 3,554,297.

Ethics Committee of the National Reference Center for Sanitary Dermatology Dona Libânia: Opinion number 3,573,192.

\section{Financial support}

Funding of the author. 


\section{Unpublished material}

The authors declare that the material has not been published in its present form in any other scientific journal.

\section{Independence of researchers from funders}

All the authors declare independence of researchers from funders.

\section{References}

1 Monteiro MJSD, dos Santos GM, Barreto MTS, Sousa Silva RV, Jesus RLR, Silva HJN. Perfil epidemiológico de casos de hanseníase em um estado do nordeste brasileiro. Rev Aten Saúde, 2017; 15(54): 21-28, doi:10.130 37/ras.vol15n54.4766.

2 Brasil. Guia prático sobre a hanseníase. Ministério da Saúde [Internet]. 2017 [Accessed April 8, 2019]. Available in: http://www.saude.gov.br/images/pdf/2017/novembro/22/Guia-Pratico-de-Hanseniase-WEB.pdf.

3 World Health Organization. Global leprosy update 2018. Genebra: World Health Organization; 2019.

4 Brasil. Boletim epidemiológico hanseníase. Ministério da Saúde [Internet]. 2020 [Accessed April 8, 2019]. Available in: https://www.saude.gov.br/images/pdf/2020/janeiro/31/Boletim-hanseniase-2020-web.pdf.

5 Faria CRS, Fregonesi CEPT, Corazza DAG, Andrade DM, Mantovani NADT, Silva JR et al. Grau de incapacidade física de portadores de hanseníase: estudo de coorte retrospectivo. J Arquivos de Ciências da Saúde, 2015; 22(4): 58-62, doi:10.17696/2318-3691.22.4.2015.122.

6 Castro S, Leite C, Osterbrock C, Santos M, Adery R. Avaliação de Saúde e Deficiência: Manual do WHO Disability Assessment Schedule (WHODAS 2.0). Uberaba: Universidade Federal do Triângulo Mineiro-UFTM; 153 p. 2015. Available in: https://apps.who.int/iris/bitstream/handle/10665/43974/9788562599514_por.pdf;jse ssionid=FDA0D151963AFE4DC00776A93E4B5FC6? sequence $=19$.

7 Üstün TB, Kostanjsek N, Chatterji S, Rehm J. Measuring health and disability: Manual for WHO disability assessment schedule WHODAS 2.0: World Health Organization; 2010. Available in: https://apps.who.int/iris/h andle/10665/43974.

8 Fleck MP, Louzada S, Xavier M, Chachamovich E, Vieira G, Santos L et al. Aplicação da versão em português do instrumento abreviado de avaliação da qualidade de vida "WHOQOL-bref". J Revista de Saúde Pública, 2000; 34: 178-183, doi:10.1590/S0034-89102000000200012.

9 Moura EG, Araújo APM, Silva MCR, Cardoso BA, Holanda MCS, Conceição AO et al. Relação entre a Classificação Internacional de Funcionalidade, Incapacidade e Saúde (CIF) e a limitação de atividades e restrição à participação de indivíduos com hanseníase. Cad Saúde Colet, 2017; 25(3): 355-361, doi:10.1590/1414-462 X201700030336.

10 Ikehara E, Nardi SMT, Ferrigno ISV, Pedro HSP, Paschoal VDAJA. Escala Salsa e grau de Incapacidades da Organização Mundial de Saúde: avaliação da limitação de atividades e deficiência na hanseníase. Acta Fisiatr, 2010; 17(4): 169-174, doi:10.5935/0104-7795.20100001.

11 Freitas ALP, Rodrigues SG. A avaliação da confiabilidade de questionários: uma análise utilizando o coeficiente alfa de Cronbach. In: Anais do XII Simpósio de Engenharia de Produção; 2005 Nov 7-9; São Paulo, Brasil. SIMPEP; 2005. Available in: https://simpep.feb.unesp.br/anais/anais_12/copiar.php?arquivo=Freitas_ALP_A $\% 20$ avalia\%E7\%E3o\%20da\%20confiabilidade.pdf.

12 Dancey C, Reidy J. Estatística sem matemática para psicologia. 7th ed, Porto Alegre, RS: Penso, 2013.

13 BRASIL. Conselho Nacional de Saúde. Resolução N ${ }^{\circ}$ 466, de 12 de dezembro 2012. Diário Oficial da União. 2012; Poder Executivo, Brasil, DF, 13 jun. 2013. Seção 1, n. 112, p. 59-62. Available in: http://conselho.saude .gov.br/resolucoes/2012/Reso466.pdf.

14 Pilatti LA, Pedroso B, Gutierrez GL. Propriedades psicométricas de instrumentos de avaliação: um debate necessário. J Revista Brasileira de Ensino de Ciência e Tecnologia, 2010; 3(1): 81-91, doi:10.3895/S1982873X2010000100005

15 Alexandre NMC, Gallasch CH, Lima MHM, Rodrigues RCM. A confiabilidade no desenvolvimento e avaliação de instrumentos de medida na área da saúde. J Revista Eletrônica de Enfermagem, 2013; 15(3): 800-807, doi:1 $0.5216 /$ ree.v15i3.20776.

16 Barbosa KSS, Castro SS, Leite CF, Nacci FR, Accioly MFJC, Coletiva S. Validação da versão brasileira do World Health Organization Disability Assessment Schedule 2.0 em indivíduos HIV/AIDS. Ciênc Saúde Coletiva, 2020; 25(3): 837-844, doi:10.1590/1413-81232020253.18992018.

17 Castro SS, Leite CF, Baldin JE, Accioly MFJFM. Validation of the Brazilian version of WHODAS 2.0 in patients on hemodialysis therapy. Fisioterapia em Movimento, 2018; 31: 1-13, doi:10.1590/1980-5918.031.ao30. 
18 Martins GA. Sobre confiabillidade e validade. J Revista Brasileira de Gestão de Negócios, 2006; 8(20): 1-12, Available in: http://www.spell.org.br/documentos/ver/6471/sobre-confiabilidade-e-validade/i/pt-br.

19 Park SH, Demetriou EA, Pepper KL, Song YJC, Thomas EE, Hickie IB et al. Validation of the 36-item and 12-item self-report World Health Organization Disability Assessment Schedule II (WHODAS-II) in individuals with autism spectrum disorder. Autism Res, 2019; 12(7): 1101-1111, doi:10.1002/aur.2115.

20 Souza AC, Alexandre NMC, Guirardello EB. Propriedades psicométricas na avaliação de instrumentos: avaliação da confiabilidade e da validade. J Epidemiologia e Serviços de Saúde, 2017; 26: 649-659, doi:10.5123/s1 679-49742017000300022.

21 Ribeiro GC, Lana FCF. Incapacidades físicas em hanseníase: caracterização, fatores relacionados e evolução. Cogitare Enfermagem, 2015; 20(3): 496-503, doi:10.5380/ce.v20i3.41246.

22 Kutlay Ş, Küçükdeveci AA, Elhan AH, Öztuna D, Koç N, Tennant A. Validation of the World Health Organization disability assessment schedule II (WHODAS-II) in patients with osteoarthritis. Rheumatol Int, 2011; 31(3): 339-346, doi:10.1007/s00296-009-1306-8.

23 Magistrale G, Pisani V, Argento O, Incerti CC, Bozzali M, Cadavid D et al. Validation of the World Health Organization Disability Assessment Schedule II (WHODAS-II) in patients with multiple sclerosis. Mult Scler $J, 2015 ; 21(4)$ : 448-456, doi:10.1177/1352458514543732.

24 Nardi SM, Paschoal VA, Chiaravalloti-Neto F, Zanetta DM. Deficiência após a alta medicamentosa da hanseníase: prevalência e distribuição espacial. Revista de Saúde Pública, 2012; 46(6): 969-977, doi:10.159 0/s0034-89102013005000002.

25 Neves TV, Souza EB, Valentim IM, Reis IB, Diniz APM, Rocha ESD et al. Grau de incapacidade física e escore olhos-mãos-e-pés em pacientes hansênicos pós-alta. Revista de APS, 2015; 18: Available in: https://periodicos. ufjf.br/index.php/aps/article/view/15565/8167.

26 Heidinger M, Simonnet E, Karippadathu SF, Puchinger M, Pfeifer J, Grisold A. Analysis of Social Determinants of Health and Disability Scores in Leprosy-Affected Persons in Salem, Tamil Nadu, India. Int J Environ Res Public Health, 2018; 15(12): doi:10.3390/ijerph15122769. 